\title{
These Boots Weren't Made for Walking: Gendered Discrepancies in Wearing Painful, Restricting, or Distracting Clothing
}

\author{
Renee Engeln ${ }^{1}$ iD $\cdot$ Anne Zola ${ }^{2} \mathbb{D}$
}

Accepted: 18 June 2021 / Published online: 19 August 2021

(c) The Author(s), under exclusive licence to Springer Science+Business Media, LLC, part of Springer Nature 2021

\begin{abstract}
Using the framework of objectification theory (Fredrickson \& Roberts in Psychology of Women Quarterly 21(2): 173-206, 1997), the current studies explored how often women (vs. men) reported wearing clothing that is painful, distracting, and/ or restricting (PDR clothing). Additionally, we examined differences in body surveillance (i.e., chronically monitoring the appearance of one's body) and body appreciation between those who reported wearing various types of PDR clothing and those who did not. In both a sample of U.S. college students $(n=545)$ and a broader sample of U.S. adults $(n=252)$, results indicated that women were substantially more likely to wear PDR clothing than men. Across both samples, the largest differences between men and women were in wearing uncomfortable or painful shoes and in wearing clothing that is distracting because it requires ongoing monitoring or adjusting. Women and men with higher body surveillance were more likely to report wearing PDR clothing. Though some findings pointed toward a negative association between body appreciation and wearing PDR clothing, these results were inconsistent. Overall, results were consistent with the notion that the gendered nature of clothing might reflect and provoke chronic vigilance of the body's appearance. Gendered differences in the extent to which clothing promotes comfort and movement vs. discomfort and distraction has clear implications for women's quality of life.
\end{abstract}

Keywords Objectification $\cdot$ Clothing $\cdot$ Sex roles $\cdot$ Body surveillance $\cdot$ Body appreciation $\cdot$ Gender $\cdot$ Fashion

- "My mom used to always say, "It hurts to be beau-

tiful." Sometimes you have to sacrifice comfort for

style." - Comment from a study participant

In a 2017 article in Quartz, writer Lucy Rycroft-Smith described how her decision to begin wearing men's clothing brought to light the impact women's fashions can have on the experience of day-to-day life (Rycroft-Smith, 2017). She explained,

"For most of my life, I've worn clothing that leaves a mark. Bra straps nip at my shoulders; the backs of my shoes dig into my skin. Pantyhose leaves red rings around my stomach at the end of the day-glaring, and just as affecting, as felt-tip marks from a plastic sur-

Renee Engeln

rengeln@northwestern.edu

1 Department of Psychology, Northwestern University, Evanston, IL 60208, USA

2 Department of Medical Social Sciences, Feinberg School of Medicine, Northwestern University, Chicago, IL, 60611, USA geon.... I've spent 20 years wearing clothes designed to make me feel ill at ease-in both my body and mind" (Rycroft-Smith, 2017).

A 2017 opinion piece in the Washington Post described women's fashions as "providing a source of ongoing distraction, discomfort, or both" (Engeln, 2017). Although anecdotal evidence supports the notion that women's fashions can lead to pain and distraction (and that women's fashions are more likely to do so than men's fashions), little empirical research has examined this topic. Using the framework of objectification theory (Fredrickson \& Roberts, 1997), the current studies offer an exploratory, descriptive analysis of differences in the frequency with which women and men wear clothing that is painful, distracting, and/or restricting. We also investigated how these clothing choices were associated with body surveillance (a manifestation of self-objectification) and body appreciation (an indicator of positive body image). Finally, we conducted an exploratory analysis of self-reported reasons for wearing such clothing. 


\section{Women's Clothing and Body Image}

Research exploring the associations between women's clothing choices and body image is scarce (Tiggemann \& Andrew, 2012; Tiggemann \& Lacey, 2009). This gap in the literature is notable given that selecting specific types of apparel can act as an intentional, public expression of both positive and negative body image. For example, women who are less satisfied with their body shape are more likely to select clothing that conceals their body (Butler \& Scheetz, 1998; Tiggemann \& Andrew, 2012; Tiggemann \& Lacey, 2009). Similarly, women indicate that when they "feel fat" they are more interested in clothing that camouflages their body (Kwon \& Parham, 1994). In contrast, women who are more satisfied with their body are more likely to enjoy shopping for clothing (Tiggemann \& Lacey, 2009).

Even trying on clothing can be an emotionally loaded experience for women, especially if the clothing is revealing (Tiggemann \& Andrew, 2012). In experimental studies, researchers have demonstrated that trying on a bathing suit increases body shame and state self-objectification in women (Fredrickson et al., 1998; Hebl et al., 2004). One study found that when imagining trying on bathing suits in a store with a friend, $76 \%$ of college women said the activity would prompt them to engage in negative body talk with that friend (Engeln-Maddox et al., 2012). A different study of college women found that, when asked to imagine how their lives would change if they looked more like the media-promoted beauty ideal, $46 \%$ spontaneously listed a happier experience shopping for clothing as a likely positive outcome of having a more "ideal" body shape (EngelnMaddox, 2006).

\section{Gender, Clothing Choices, and Self-Objectification}

One of the fundamental premises of Fredrickson and Roberts' (1997) objectification theory is that ongoing sexually objectifying experiences are internalized over time, leading women to selfobjectify. Self-objectification involves taking a habitual, thirdperson perspective focusing on the outward appearance of one's body. It is marked by frequent monitoring of the body's appearance (often operationalized as body surveillance; McKinley \& Hyde, 1996). A wealth of research has linked this type of body surveillance to body dissatisfaction and body shame (Calogero et al., 2005; Miner-Rubino et al., 2002; Schaefer et al., 2018; Tiggemann \& Kuring, 2004), perhaps because chronic appearance monitoring provides ongoing opportunities to compare one's own body to cultural beauty ideals (Fitzsimmons-Craft et al., 2012). Many types of women's fashions provide ready triggers for body surveillance because they require ongoing attention and adjustment. As Fredrickson and Roberts (1997) put it, "Certain necklines and hemlines require regular body monitoring. In wearing these fashions a woman is forced to be chronically vigilant about whether undergarments or 'too much skin' are (shamefully) exposed, all while maintaining the illusion that she is at ease dressed as she is" (p. 182).

The vigilance required by some types of women's apparel is even common in clothing marketed for young girls (American Psychological Association, 2007). This trend reinforces the idea that being a girl (or woman) entails the ongoing monitoring of your clothes - either by yourself or by others. Martin (1998) conducted a semi-structured observational study at five different pre-schools and concluded that clothing was regularly a source of distraction for girls, as adults intervened to straighten bows or yank up tights. Similarly, Martin argued that the ways these young girls were dressed often inhibited their ability to move (for example, they could not kick up their legs freely if wearing a skirt). Consistent with these observations, a recent analysis of hundreds of Halloween costumes, Valentine's Day cards, and dolls/actions figures revealed that $88 \%$ of the female characters wore decorative articles of clothing that could impede movement (like a very long dress), whereas $78 \%$ of male characters wore functional clothing designed to facilitate movement (Murnen et al., 2016). These findings are consistent with Jeffreys' (2015) argument that men's fashions are nearly always more functional and comfortable than women's fashions. Jeffreys notes that men's fashions rarely include non-usable pockets, cut-outs designed to reveal skin, or skintight articles of clothing that make movement difficult. These elements are all commonly featured in women's fashions.

Viewing the body more in terms of how it looks than how it feels is one way to conceive of self-objectification (Noll \& Fredrickson, 1998). Women's fashions often reinforce this trade-off, with tight, short, or low-cut outfits limiting women's ability to move freely. Indeed, a number of authors have noted that part of gender socialization involves teaching the lesson that "boys act and girls appear" (Murnen et al., 2016). As Stephens et al. (1994) wrote, "a boy learns to view his body primarily as a means of achieving mastery over the external environment, a girl learns that a main function of her body is to attract others" (p. 144). In other words, boys' bodies are for doing things, whereas girls' bodies are for being looked at. This psychological divide may be reflected in gendered clothing choices. For example, one qualitative analysis of young men's views on clothing found that their focus when selecting apparel was on comfort, function, and practicality (Frith \& Gleeson, 2004). Young women, on the other hand, report being more motivated by factors like the look and style of clothing (Taylor \& Cosenza, 2002). 
Not all clothing choices are freely made. For example, specific types of apparel may be required or at least expected in certain workplaces. Nonetheless, in some cases, women's decisions to wear painful, distracting, and/or restricting clothing (referred to as PDR clothing for the remainder of this paper) could be viewed as a manifestation of self-objectification. Tiggemann and Andrew (2012) found that, among women, wearing more comfortable clothing was negatively correlated with self-objectification, whereas fashion-based motivations were positively correlated with self-objectification. Similarly, in a study of women who worked out at gyms, Prichard and Tiggemann (2005) found that women who wore baggier clothing while exercising reported lower levels of body surveillance compared to those who exercised in form-fitting apparel. Wearing PDR clothing ranks high among the behaviors women (but not men) report engaging in to "look sexy" (Smolak et al., 2014). Specifically, women reported wearing high heels and lowcut shirts or other revealing clothing when they wanted to look sexy. Women who report feeling more pressure to dress in sexualized clothing score higher on body surveillance (Smith et al., 2017).

\section{The Current Research}

The current research involved two exploratory, predominantly descriptive studies examining the frequency with which men and women reported wearing different types of PDR clothing. We surveyed college men and women (Study 1) and a general sample from an online survey platform (Study 2) about whether and how often they wore such clothing. Participants also completed two body image-related measures. A university institutional review board approved both studies.

\section{Study 1}

In Study 1, a convenience sample of college students completed an online survey described as a "Clothing Survey." The survey contained questions about wearing PDR clothing along with measures of body appreciation and body surveillance. We predicted that women would be more likely to endorse all PDR questions with the exception of a question about wearing clothes that are "too hot (or too covered) for weather conditions" (as men are sometimes required to wear suit coats or long-sleeved shirts at work or formal social events even in warm weather).

Body appreciation is an element of positive body image that includes unconditional acceptance of the body (regardless of weight, shape, or perceived imperfections) as well as attention to and respect for the body's needs (Tylka \&
Wood-Barcalow, 2015). Several studies have linked taking a functional view of one's body (e.g., focusing on what the body can do and how it feels) with higher body appreciation in women (e.g., Alleva et al., 2015; Stern \& Engeln, 2018; Wood-Barcalow et al., 2010). Additionally, a program designed to encourage a focus on body functionality in women with negative body image led to increased body appreciation (Alleva et al., 2015). Because women's fashions tend to emphasize appearance over functionality and limit the body's ability to move or the wearer's ability to comfortably breathe (Jeffreys, 2015), we predicted that wearing PDR clothing would be associated with lower body appreciation among women. Likewise, because adopting a more internal/ functional perspective (i.e., focusing on internal processes, bodily capabilities, and self-care) is an alternative to taking an objectified perspective of one's body (Homan \& Tylka, 2015; Noll, 1996; Stern \& Engeln, 2018), we predicted that, among women, wearing PDR clothing would be associated with higher body surveillance. Although there is less available work investigating men's fashions and body image, we tentatively extended these correlational predictions regarding wearing PDR clothing, body surveillance, and body appreciation to men in our sample.

\section{Method}

Generation of Types of PDR Clothing. A group of ten research assistants (nine women and one man) conducted Internet searches to generate lists of types of PDR clothing. Search terms included "uncomfortable clothing," "clothing that hurts," "clothing that is distracting," "clothing that is bad for your health," and "wardrobe malfunction" along with searches replacing the word "clothing" with "fashion." No specific guidelines were followed for number of search hits to read/examine. Along with the first author, the group then engaged in discussion to generate a list of common ways in which clothing could be painful, restricting, or limit movement. Consistent with Fredrickson and Roberts' (1997) arguments about how clothing could relate to selfobjectification and Martin's (1998) discussion of clothing that requires adjusting throughout the day, we included types of clothing that could cause distraction or require ongoing monitoring in addition to clothing that explicitly causes pain or prevents freedom of movement. We excluded references to clothing that could be distracting to other people (i.e., not the wearer).

After compiling the examples generated by individual group members, we worked together to generate a list of types of PDR clothing with the goals of a) creating categories that would be inclusive of the specific articles of clothing mentioned in search results; b) making the list of PDR clothing as gender-inclusive as possible (i.e., limiting 
references to specific, gendered articles of clothing when it made sense to do so) and c) focusing (when possible) on the impact of a type of PDR clothing in order to create broad categories rather than an exhaustive list of articles of clothing that might qualify as PDR. For example, "skinny jeans" were frequently mentioned in search results, but instead of writing a question about skinny jeans specifically, we read relevant search results to determine how/why skinny jeans might qualify as PDR clothing (e.g., because they make it difficult to breathe, because they bite into one's skin and leave marks). Thus, where it was logical to do so, we framed questions in terms of the PDR-relevant effects of clothing that could be experienced by any gender rather than specific articles of clothing or fashion accessories. We did retain reference to shoes as a specific article of clothing based on the substantial amount of literature on the discomfort associated with high heels (e.g., Jeffreys, 2015; Parmentier, 2016; Reynolds et al., 2018) and the fact that all genders regularly wear shoes of some sort. Two questions asked about shoes outright but again focused on the PDR effects of shoes (shoes that cause pain/blisters and shoes that limit the time one can comfortably stand) rather than a specific type of shoe. We retained two items that would rarely apply to men (skirts/dresses that can unintentionally reveal more of the body than the wearer intended and clothing that requires monitoring in order to avoid accidentally exposing the breasts) because these specific issues were frequently mentioned as "wardrobe malfunctions" that require monitoring to avoid. Otherwise, the types of PDR clothing generated by the research group could be included in both men's or women's standard fashions (e.g., clothes that make it difficult to bend over). All research team members reviewed the final list for clarity and to determine whether each category had face validity in terms of being painful, distracting, or restricting. See Appendix for all PDR questions.

Participants. Participants were college undergraduates from the U.S. Because substantially more women responded to the survey initially, we limited participation in the survey to only those who identified as men for an additional period until the sample sizes for men and women were similar. The gender identity question in the survey did not require participants to identify as cisgender men or women to be included in these groups. Participants who did not identify as a man or woman $(n=5)$ could complete the survey when it was initially open, but were excluded from analyses because they could not be classified for an analysis of differences between men and women. Two hundred and eighty-four men $\left(M_{\text {age }}=20.0, S D=1.9\right)$ and 261 women $\left(M_{\text {age }}=19.8\right.$, $S D=1.2)$ remained in the sample after these exclusions. The majority were White/Caucasian $(66 \%, n=360)$, followed by Asian/Asian American/Pacific Islander (19\%, $n=106)$,
Hispanic/Latino (5\%, $n=29)$, Multiracial $(6 \%, n=29)$, and Black/African American (2\%, $n=9)$, with 2\% $(n=12)$ not reporting race/ethnicity or reporting a different ethnicity than those listed.

Procedure. All data were collected prior to the beginning of the COVID-19 pandemic. Using various social media platforms and online forums (e.g., Facebook, Reddit, etc.), we distributed an online survey hosted by Qualtrics. Undergraduate college students in the U.S. were invited to participate in a brief online "Clothing Survey." Participants could choose to enter a raffle for a 1 in 10 chance of winning a $\$ 10$ gift card as thanks for their time. To help ensure that participants were college students, the raffle entry required a.edu email address. We asked participants a series of "yes" or "no" questions about whether they ever wore specific types of PDR clothing or accessories (see Appendix). For example, we asked, "Do you ever wear clothes that make it hard to walk or move your legs freely?" and "Do you ever wear shoes that cause pain or blisters?" We worded questions to emphasize the impact wearing the clothing item has on the individual rather than the article of clothing itself. Those who responded "yes" to a given PDR clothing type were then asked to estimate how often they wore that type of clothing (1 - Less than once a month, 2 - Once a month, 3-2-3 times per month, 4-Once a week, 5-2-4 times per week, 6 - Every day or nearly every day). Participants who responded "no" to a PDR clothing question were coded as 0 (Never) for frequency analyses. We presented two questions exclusively to women ("Do you ever wear dresses or skirts that you have to monitor so that they don't blow up or flip up and reveal more skin than you wish to show?" and "Do you ever wear clothes that you have to be careful in because there is a risk of unintentionally exposing your breasts?"). Although there are some men to whom these questions might apply, we imagined that low base rates among men would make these two questions more distracting than useful if presented to men. In addition to the PDR questions, participants completed a measure of body appreciation and a measure of body surveillance, followed by basic demographic questions. Order of all measures was counterbalanced.

\section{Measures}

Body Appreciation. The Body Appreciation Scale-2 (BAS2; Tylka \& Wood-Barcalow, 2015) is a positive body image measure that assesses the extent to which a participant respects and feels favorably toward their body. Participants rate how often statements like "I feel good about my body" and "I take a positive attitude towards my body" are true for them, from 1 (Never) to 5 (Always). The average of the 10 items creates a total body appreciation score, with higher 
scores indicating a more compassionate and favorable outlook toward one's body. Among women and men, higher scores on the BAS-2 are inversely related to body dissatisfaction, body surveillance, and internalization of media appearance ideals (Andrew et al., 2015; Tylka \& Wood-Barcalow, 2015). Tylka and Wood-Baraclow (2015) reported Cronbach's alphas of .94 and .93 for college women and men, respectively. In the current sample, alphas were .93 for women and .94 for men.

Body Surveillance. The body surveillance subscale from the Objectified Body Consciousness Scale (McKinley \& Hyde, 1996) assesses the extent to which an individual monitors their outward appearance (e.g., "I often worry about whether the clothes I am wearing make me look good"). Responses are rated from 1 (Strongly Disagree) to 7 (Strongly Agree), with higher scores indicating greater appearance and body monitoring. For both men and women undergraduates, body surveillance is correlated with lower levels of body esteem and greater body dissatisfaction (Frederick et al., 2007; Moradi \& Varnes, 2017). Researchers have reported alphas of .79 for both undergraduate men (McKinley, 1998) and women (McKinley \& Hyde, 1996). In the current sample, alphas were .87 and .84 for college men and women, respectively.

\section{Results}

Data Cleaning and Analytic Approach. For PDR questions presented to men and women, overall missingness was . $3 \%$, with no item having more than $1 \%$ missingness. Two questions were exclusively presented to women; these questions showed .2\% missingness with neither item displaying more than $1 \%$ missingness. PDR clothing types were evaluated individually using available data for each question. Body image variables were similarly complete; overall missingness among body surveillance and body appreciation items was . $3 \%$ and no item had more than $1 \%$ missing data. Fivehundred nine participants had no missing data for either PDR questions or body image-related measures. Given the low levels of missing data and consistent with recommendations by Parent (2013), available item analysis (i.e., pairwise deletion) was used. Shapiro-Wilks tests showed a departure from normality for both body surveillance, $W(541)=.98, p<.001$, and body appreciation, $W(545)=.99, \mathrm{p}<.001$. However, Shapiro-Wilks is extremely conservative with larger samples and Q-Q plots of body surveillance and body appreciation revealed very minor deviations from normality (see supplementary material here). Given that ANOVA is robust against minor violations of normality (Schmider et al., 2010), we proceeded with standard analysis of variance.
In order to test gender discrepancies in the types of PDR clothing worn, we first conducted a series of chi-square tests on thirteen of the fifteen clothing questions (excluding the two questions presented only to women). All tests met the chi-square assumption of at least five participants in each cell. We also report the percent of men and women who indicated they wear the PDR clothing type at least once a week or more and again ran a series of chi-square tests to test for differences between men and women. Finally, we conducted a series of 2 (gender: man, woman) $\times 2$ (wears type of PDR clothing: yes, no) factorial ANOVAs to examine the effect of gender, PDR clothing, and their interaction on body surveillance and body appreciation. For PDR clothing questions presented only to women, we conducted one-way ANOVAs.

There is no research to date establishing a scale that measures a single PDR construct. Further, some types of PDR clothing (e.g., clothing that limits your ability to breathe) might be more impactful than others (e.g., clothing that can drag on the ground), so we chose to treat wearing a specific PDR clothing type as a distinct independent variable rather than aggregating PDR types for analyses. However, a disadvantage of this approach is that conducting multiple tests can increase the risk of Type 1 error. Given the increased risk of false positives, we discuss only results that are significant at the .01 level.

Differences between Men and Women in Wearing PDR Clothing. Consistent with predictions, women were significantly more likely than men to indicate they "ever" wear painful, distracting, and/or restricting clothing for twelve of the thirteen types of clothing ( $p s<.00001$; see Table 1 for full results). Clothing that leaves one too hot for weather conditions was the only type that did not show this pattern $(p=.68)$. Where there were gender discrepancies, women were between 2 and 12 times more likely than men to wear PDR clothing. Effect sizes revealed the largest gender discrepancies were with respect to wearing shoes that limit how long one can comfortably stand (Cramer's $\mathrm{V}=.56,77 \%$ of women, $21 \%$ of men), wearing shoes that cause pain or blisters (Cramer's $\mathrm{V}=.53,76 \%$ of women, $23 \%$ of men), and wearing clothes that leave red marks or welts on one's body (Cramer's V $=.46,55 \%$ of women, $12 \%$ of men). Thirteen percent of men $(n=38)$ and one percent of women $(n=3)$ reported they did not wear any of the types of PDR clothing.

If participants indicated that they have ever worn a type of PDR clothing, they were then asked to indicate how often they wear that type of clothing. For brevity, the full data from the ordinal frequency scale (ranging from less than once a month to every day or nearly every day) for men and women for each question is available in supplementary materials online. For analyses, participants who indicated they 
Table 1 Gender Differences in "Ever Wearing” PDR Clothing Types (Study 1, College Student Sample)

\begin{tabular}{|c|c|c|c|c|}
\hline Do you ever wear... & Women & Men & & Cramer's V \\
\hline 1. shoes that cause pain or blisters? & $197(76 \%)$ & $66(23 \%)$ & $* * * *$ & .53 \\
\hline 2. clothing that causes discomfort because it is itchy or scratchy? & $102(39 \%)$ & $53(19 \%)$ & $* * * *$ & .23 \\
\hline 3. clothing that you have to regularly adjust or monitor to keep it in the right place? & $208(80 \%)$ & $108(38 \%)$ & $* * * *$ & .42 \\
\hline 4. clothes that make it hard to move your arms freely? & $100(38 \%)$ & $52(18 \%)$ & $* * * *$ & .22 \\
\hline 5. clothes that make it hard to walk or move your legs freely? & $87(33 \%)$ & $51(18 \%)$ & $* * * *$ & .18 \\
\hline 6. clothes that make it difficult to bend over? & $149(57 \%)$ & $46(16 \%)$ & $* * * *$ & .42 \\
\hline 7. clothes that leave red marks/welts on your body after you take them off? & $144(55 \%)$ & $35(12 \%)$ & $* * * *$ & .46 \\
\hline 8. tight-fitting clothes that make it hard to take deep breaths? & $78(30 \%)$ & $17(6 \%)$ & $* * * *$ & .31 \\
\hline $\begin{array}{l}\text { 9. dresses or skirts that you have to monitor so that they don't blow up (or flip up) and reveal more } \\
\text { skin than you wish to show? }\end{array}$ & $208(80 \%)$ & $\mathrm{n} / \mathrm{a}$ & & \\
\hline $\begin{array}{l}\text { 10. clothes that you have to be careful in because there is a risk of unintentionally exposing your } \\
\text { breasts? }\end{array}$ & $145(56 \%)$ & $\mathrm{n} / \mathrm{a}$ & & \\
\hline 11. clothes that make you too hot (or too covered) for weather conditions? & $130(50 \%)$ & $147(52 \%)$ & & .02 \\
\hline 12. clothes that make you too cold (or too uncovered) for weather conditions? & $181(69 \%)$ & $96(34 \%)$ & $* * * *$ & .35 \\
\hline 13. shoes that limit how long you can comfortably stand? & $200(77 \%)$ & $59(21 \%)$ & $* * * *$ & .56 \\
\hline 14. clothing that you have to be careful in because it can drag on the ground? & $63(24 \%)$ & $22(8 \%)$ & $* * * *$ & .23 \\
\hline 15. accessories (e.g., bracelets, earrings, necklace, watch) that can catch on things? & $185(71 \%)$ & $117(41 \%)$ & $* * * *$ & .30 \\
\hline
\end{tabular}

Asterisks indicate $p$-values for chi-square tests

$* * p<.01 ; * * * p<.001 ; * * * * p<.0001$

did not wear a specific type of PDR clothing were coded as 0 (Never). To provide an overall picture of the percent of men vs. women who reported regularly wearing different types of PDR clothing, Table 2 presents the percent who indicated

Table 2 Number (and Percent) of Men and Women Wearing PDR Clothing Types Once a Week or More (Study 1 and Study 2)

\begin{tabular}{llllll}
\hline & \multicolumn{2}{l}{$\begin{array}{l}\text { Study 1 (College } \\
\text { sample) }\end{array}$} & \multicolumn{2}{l}{$\begin{array}{l}\text { Study 2 (MTurk } \\
\text { sample) }\end{array}$} \\
\cline { 2 - 3 } \cline { 5 - 6 } PDR clothing type & Women & Men & & Women & Men \\
\hline 1. Shoe pain/blisters & $44(17 \%)$ & $26(9 \%)$ & $10(8 \%)$ & $7(6 \%)$ \\
2. Itchy/scratchy & $15(6 \%)$ & $12(4 \%)$ & $3(2 \%)$ & $4(3 \%)$ \\
3. Adjust/monitor & $91(35 \%)$ & $76(27 \%)$ & $36(28 \%)$ & $19(16 \%)$ \\
4. Restrict arms & $12(5 \%)$ & $19(7 \%)$ & $6(5 \%)$ & $7(6 \%)$ \\
5. Restrict legs & $24(9 \%)$ & $26(9 \%)$ & $11(8 \%)$ & $7(6 \%)$ \\
6. Restrict bending & $35(13 \%)$ & $15(5 \%)$ & $9(7 \%)$ & $7(6 \%)$ \\
7. Red marks/welts & $84(32 \%)$ & $25(9 \%)$ & $19(14 \%)$ & $13(11 \%)$ \\
8. Restrict breathing & $9(3 \%)$ & $3(1 \%)$ & $4(3 \%)$ & $1(1 \%)$ \\
9. Monitor dress/skirt & $30(11 \%)$ & $\mathrm{n} / \mathrm{a}$ & $16(12 \%)$ & $\mathrm{n} / \mathrm{a}$ \\
10. Monitor breasts & $30(12 \%)$ & $\mathrm{n} / \mathrm{a}$ & $11(8 \%)$ & $\mathrm{n} / \mathrm{a}$ \\
11. Too hot/covered & $37(14 \%)$ & $67(24 \%)$ & $27(21 \%)$ & $13(11 \%)$ \\
12. Too cold/uncovered & $59(23 \%)$ & $43(15 \%)$ & $14(11 \%)$ & $8(7 \%)$ \\
13. Shoes limit standing & $38(15 \%)$ & $26(9 \%)$ & $17(13 \%)$ & $8(7 \%)$ \\
14. Drag on ground & $5(2 \%)$ & $7(2 \%)$ & $10(8 \%)$ & $6(5 \%)$ \\
15. Catch on things & $134(51 \%)$ & $97(34 \%)$ & $53(40 \%)$ & $27(22 \%)$ \\
\hline
\end{tabular}

Percentages are calculated within gender wearing each type of PDR clothing at least once a week or more (i.e., responses 4, 5, or 6 on the response scale).

For wearing the types of PDR clothing once a week or more, all but one type (clothing that restricts breathing) met the assumption of 5 or more respondents in each cell, leaving 12 types of PDR clothing for analyses by gender. Women were significantly more likely than men to wear 4 of the 12 PDR types at least once a week ( $p s \leq .007)$; these types were clothing that leaves red marks/welts, clothing that can catch on things, clothing that restricts bending, and shoes that cause pain/blisters. Among these discrepancies, women were between approximately .50 and 5 times more likely than men to wear PDR clothing types once a week or more. Men were more likely than women to wear clothes that left one too hot/too covered for weather conditions once a week or more ( $p=.006 ; .50$ times as likely). The largest gender discrepancies were in relation to wearing clothing that leaves red marks/welts (Cramer's V $=.29,32 \%$ of women, $9 \%$ of men), clothing that can catch on things (Cramer's $\mathrm{V}=.17$, $51 \%$ of women, $34 \%$ of men), and clothing that restricts bending over (Cramer's $\mathrm{V}=.14,13 \%$ of women, $5 \%$ of men). Full results for these chi-square tests are in supplementary materials online.

Body Appreciation, Body Surveillance, and PDR Clothing. Body appreciation scores did not differ significantly between men $(M=3.6, S D=.9)$ and women $(M=3.5, S$ $D=.7), t(543)=.78, p=.43, d=.08,95 \%$ CI $[-.08, .19]$. 


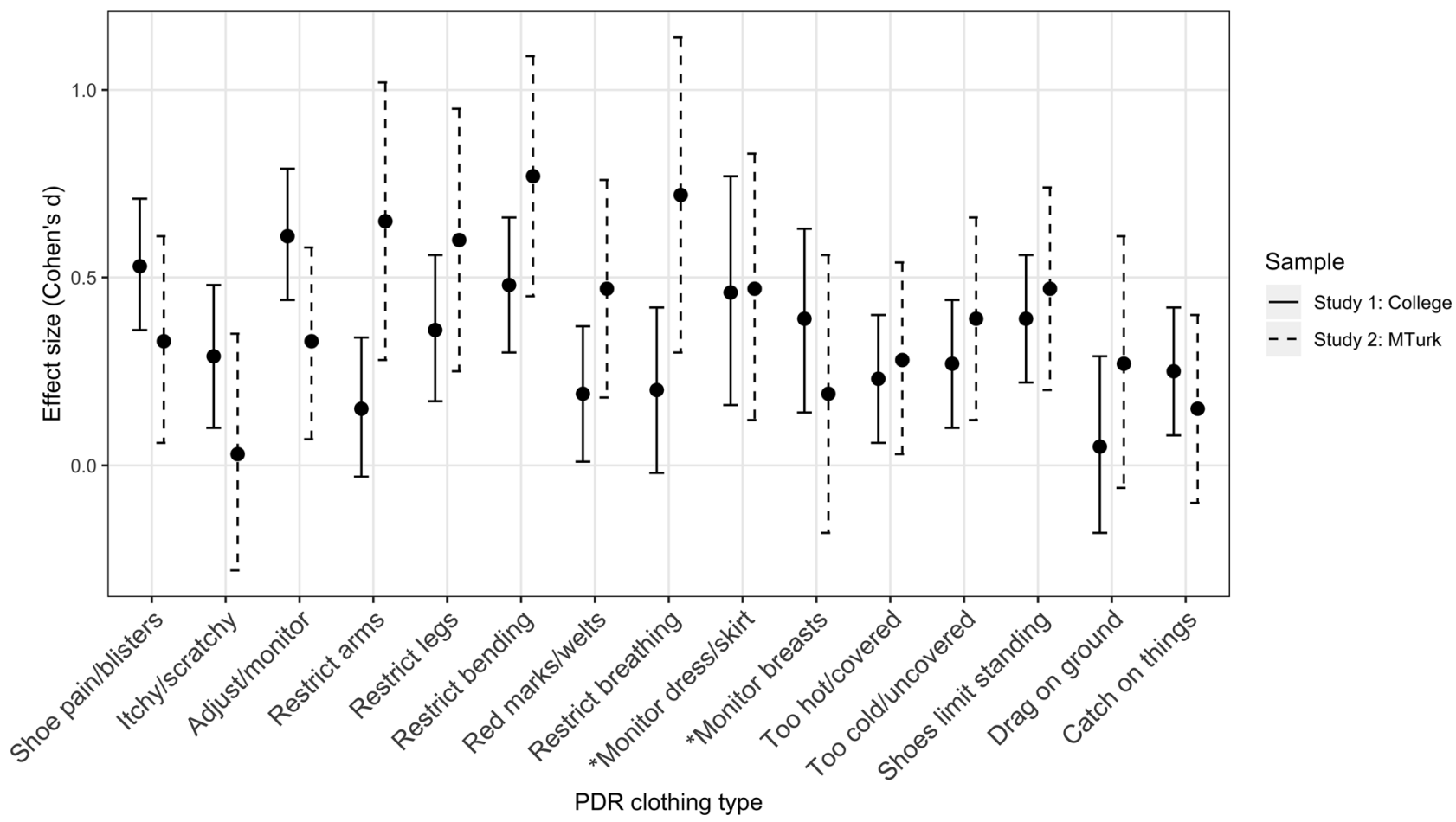

Fig. 1 Effect Sizes for Body Surveillance Discrepancies between Those Who Do and Do Not Wear PDR Clothing Types Effect size (Cohen's d) and 95\% confidence intervals displayed for effects collapsed across gender. * = women only

Women reported significantly higher body surveillance $(M=4.8, S D=1.0)$ than men $(M=4.1, S D=1.2), t(539)=$ $6.47, p<.001, d=.56,95 \%$ CI $[.44, .82]$. We conducted a series of $2 \times 2$ factorial ANOVAs to examine the main effects of gender and wearing a given type of PDR clothing on body surveillance and body appreciation. Gender included two levels (man, woman) and each PDR clothing type included two levels ("No", "Yes"). For the two clothing types presented only to women (monitor breasts, monitor skirt/dress), we conducted one-way ANOVAs to test the effect of wearing the PDR clothing type ("No", "Yes") on body surveillance and body appreciation. Effect sizes are presented in Figs. 1 and 2; full results are reported in the supplementary materials.

Results revealed a significant main effect of gender on body surveillance at a .01 significance threshold for 12 of the 13 PDR clothing types tested (for shoe pain/blisters, $p=.013)$. In other words, women tended to score higher than men on body surveillance, as noted above. Results indicated a significant main effect of wearing PDR clothing for 11 of the 15 PDR types $(p s \leq .009)$; these types were clothing that requires adjusting/monitoring, shoes that cause pain/ blisters, clothing that restricts bending over, shoes that limit time standing, clothing that restricts one's legs, clothing that leaves one too cold/uncovered, clothing that requires monitoring one's breasts, clothing that is itchy/scratchy, dresses or skirts that require monitoring, clothing that can catch on things, and clothing that leaves one too hot/covered. For all of these effects, wearing the given type of PDR clothing was associated with higher body surveillance. No interactions were significant at the .01 level.

Given the nonsignificant interactions, we collapsed across gender when interpreting the effect of PDR clothing on body surveillance. For ease of interpretation of effect sizes, we transformed the partial eta-squares into Cohen's $d \mathrm{~s}$ with 95\% confidence intervals (Figs. 1 and 2). Two effects (adjust/monitor, shoe pain/blisters) were in the moderate to large range $(.53 \leq d \mathrm{~s} \geq .61)$ and nine effects (restrict bending, monitor skirt/dress, monitor breasts, shoes limit standing, restrict legs, itchy/scratchy, too cold/uncovered, catch on things, too hot/covered) were in the small to moderate range $(.20 \leq d \mathrm{~s} \geq .48)$. For all significant effects, those who endorsed wearing PDR clothing had higher body surveillance than those who did not.

In terms of body appreciation, results revealed no significant effects of gender ( $p s \geq .23)$. There were significant effects of PDR clothing on body appreciation for 5 of the 15 PDR types $(p s \leq .004)$. These types were clothing that leaves red marks/welts, clothing that requires adjusting/ monitoring, clothing that leaves one too hot/covered, clothing that restricts breathing, and clothing that restricts one's legs. There were no significant interactions between gender 


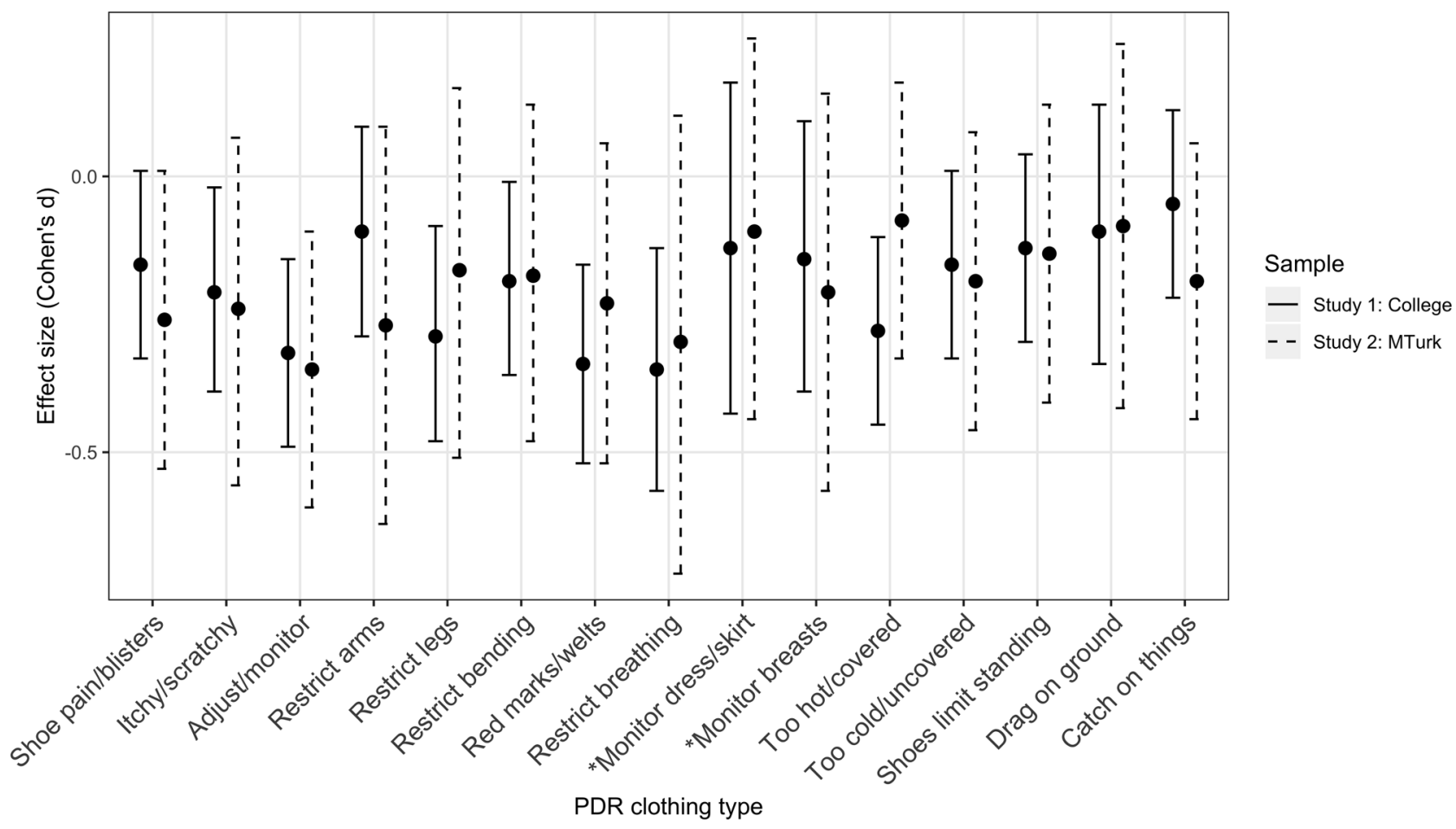

Fig. 2 Effect Sizes for Body Appreciation Discrepancies between Those Who Do and Do Not Wear PDR Clothing Types Effect size (Cohen's d) and 95\% confidence intervals displayed for effects collapsed across gender. $*=$ women only

and PDR clothing on body appreciation ( $p s \geq .14$ ), so we discuss the effects of PDR clothing on body appreciation collapsed across gender. Cohen's $d$ s for all five significant effects were in the small to moderate range $(.28 \leq d \mathrm{~s} \geq .35)$ and their direction indicated that those who wore the PDR clothing type had lower body appreciation than those who did not.

\section{Discussion}

Among a sample of U.S. college students, women were substantially more likely than men to wear nearly every type of painful, restricting, or distracting clothing listed. Clothing that requires ongoing adjusting/monitoring was among the most commonly worn types of PDR clothing. The vast majority of women (but substantially fewer men) in this sample indicated that they wear this type of PDR apparel. Overall, these findings are consistent with Fredrickson and Roberts' (1997) arguments that women's clothing frequently requires chronic vigilance. Results are also consistent with the idea that women's clothing is often not just uncomfortable, but can limit movement. For example, if you cannot comfortably stand in a pair of shoes, you also cannot do much in the way of running or walking in those shoes. Other forms of bodily restriction are even more apparent: at least one-third of the college women in this sample reported wearing clothing that limits their ability to move their arms or legs or to bend over. Just under one-third reported wearing clothing that makes it difficult to take deep breaths (compared to only $6 \%$ of men in the sample). One of the largest gender discrepancies emerged for clothing that leaves red marks or welts on one's body; over half of the college women surveyed (but only 12 percent of men) indicated that they wore such clothing, perhaps an indicator of how much more likely women's clothing is to be form-fitting compared to men's clothing. Consistent with the argument that PDR clothing can be viewed as a sign of self-objectification (or a cause of self-objectification), results revealed a trend whereby college men and women who wear PDR clothing reported higher body surveillance than their counterparts who do not wear such clothing. Without an experimental design, it is not possible to determine whether PDR clothing choices reflect already existing trait-level body surveillance, whether such clothing triggers body surveillance (by requiring additional monitoring of the body), or both.

In general, college men and women who wear PDR clothing had lower body appreciation scores than those who do not wear PDR clothing, though compared to findings for body surveillance, these differences were smaller and less consistent across PDR clothing types. Appreciating the functions of your body and focusing on its comfort could reduce the likelihood of wearing PDR clothing (or vice versa), but 
it is likely that some PDR clothing is not freely chosen (e.g., if it is required by a work uniform). This may explain why these effects were inconsistent across PDR clothing types. A stronger test of this link would involve assessing only "freely chosen" PDR clothing.

Many who reported wearing the different types of PDR clothing indicated that they did so only rarely. For example, only $3 \%$ of women and $1 \%$ of men reported wearing clothing that makes it difficult to breathe at a frequency of once per week or more. However, taken together, the pattern of results in this study suggests that many women (and some men) are spending a notable number of their waking hours in clothing that limits their ability to be comfortable or clothing that regularly distracts from what they are doing. The fact that women spend more of their lives in such clothing could have meaningful implications for quality-of-life differences between men and women.

The conclusions that can be drawn from this study are limited by the narrow, convenience sample employed; all participants were relatively young and all were college students. Study 2 was conducted to provide a second opportunity to explore the patterns identified in Study 1 in a broader sample.

\section{Study 2}

For Study 2, the online survey was identical to the survey used in Study 1 except for the addition of an open-ended question (see below). We considered exploring PDR clothing patterns in a broader sample of men and women to be important for several reasons. As noted above, in Study 1, all participants were young and currently attending college. Both of these demographic factors could substantially affect rates of wearing PDR clothing. The party/ dating scene generally associated with college life could lead young women to wear more PDR clothing in order to appear more attractive in these settings, whereas for college men, "going out" clothing does not tend to be particularly uncomfortable or restricting (Smolak et al., 2014), with the exception of (infrequently worn) formal wear. Additionally, college students are less likely to be working full-time in settings that might require PDR clothing as part of an official or unofficial dress code. Given these conflicting considerations, we did not have specific predictions for how rates of wearing PDR clothing in a broader sample might differ from a college sample. Nonetheless, we believed it was important to establish that the gender discrepancies identified in Study 1 are not unique to a college student population.

In Study 2, we added an open-ended question asking participants why they wear PDR clothing (if they do).
Objectification theory would suggest that for women, wearing uncomfortable or inconvenient fashions may be driven by pressures to meet cultural appearance ideals. However, wearing PDR clothing could also be the result of workplace requirements. Occasions like weddings or funerals may also come with implicit or explicit guidelines regarding attire. The addition of this open-ended question allowed us to conduct an initial exploration of how reasons for wearing PDR clothing might differ between men and women. We anticipated that, among those who reported wearing PDR clothing, women would be more likely than men to report appearance-driven reasons for doing so, consistent with findings that women's clothing selections are more driven by the motivation to look good (Taylor \& Cosenza, 2002).

\section{Method}

Participants and Procedure. Two-hundred seventy-four participants completed an online survey via Amazon's Mechanical Turk (MTurk; see Gardner et al., 2012 for details) and received \$1.00 upon completion of the study. After screening for attention (see below), the sample included 120 men $\left(M_{\text {age }}=38.1, S D=11.7\right.$, age range 21-69) and 132 women $\left(M_{\text {age }}=38.5, S D=11.4\right.$, age range $\left.20-72\right)$. Participants were primarily White/Caucasian $(79 \%, n=198)$, followed by African American/Black (8\%, $n=20)$, Asian/Asian American/ Pacific Islander (5\%,n=13), Hispanic/Latino $(2 \%, n=6)$, and multiracial $(2 \%, n=6)$. A few participants indicated another race/ethnicity $(n=4)$ or did not report race/ethnicity $(n=5)$. Most of the participants were employed either full-time $(78 \%, n=197)$ or part-time $(16 \%, n=41)$. Remaining participants were either not employed $(5 \%, n=13)$ or a student $(<1 \%, n=1)$.

Measures. Participants responded to the same body surveillance scale ( $\alpha=.92$ for men and .89 for women), body appreciation scale ( $\alpha=.96$ for both men and women), and PDR questions as in Study 1. Additionally, we included an open-ended question where participants could share their reasons for wearing PDR clothing: "As part of our study, we want to know some of the reasons people wear clothing that inhibits activity or does not feel good on your body. If you wear clothing that restricts your movement, is distracting, requires adjusting throughout the day, and/or causes pain or discomfort, please provide some reasons why you wear this kind of clothing in the box below."

Measures were counterbalanced except for the openended item, which always appeared last. We carefully examined all open-ended responses for evidence that participants responded thoughtfully to the question. We 
removed twenty-two participants from analyses based on this review. All excluded participants wrote clearly nonsensical responses (e.g., they copy and pasted an article from Wikipedia, answered in gibberish, etc.)

\section{Results}

Data Cleaning and Analytic Approach. PDR questions presented to both men and women showed $.4 \%$ missingness overall, with no item having more than $2 \%$ missingness. Among the two questions presented exclusively to women, overall missingness was $.8 \%$ and neither question had more than $1 \%$ missingness. As with Study 1 , PDR clothing types were analyzed individually using all available data. Body surveillance and body appreciation in Study 2 showed low levels of missingness, with $1.7 \%$ missingness overall and no more than $2 \%$ missingness for any one item. Two-hundred thirty participants had no missing data for PDR questions or the two body image measures. We used available item analysis (i.e., pairwise deletion) for analyses of body surveillance and body appreciation. Shapiro-Wilks tests revealed deviations from normality for body surveillance $W(245)=.98$, $p=.018$, and body appreciation, $W(250)=.97, p<.001$. However, as in Study 1, Q-Q plots of body surveillance and body appreciation revealed only minor deviations from normality (see supplementary material here), so we again proceeded with standard ANOVAs. The same series of chi-square tests and ANOVAs reported for Study 1 were conducted for Study 2.

Differences between Men and Women in Wearing PDR Clothing. As in Study 1, we ran a series of chi-square tests to examine whether men or women were more likely to wear different types of PDR clothing. See Table 3 for full results. Women were significantly more likely than men to endorse 5 of the 13 PDR types (catch on things, shoes that limit standing, adjust/monitor, shoe pain/blisters, red marks/welts) at the .01 level ( $p s \leq .006)$ No PDR types were endorsed by significantly more men than women. Where there were significant gender discrepancies, women were approximately 2 to 4 times more likely than men to wear PDR clothing. The largest gender discrepancies were with respect to wearing accessories that could catch on things (Cramer's V $=.34$, $61 \%$ women, $28 \%$ men), shoes that limit the time one can comfortably stand (Cramer's $\mathrm{V}=.28,45 \%$ women and $18 \%$ men), clothing that requires adjusting or monitoring (Cramer's V $=.24,55 \%$ women and $30 \%$ men), and shoes that cause pain or blisters (Cramer's V $=.24,42 \%$ women and $20 \%$ men).

See supplementary materials here for full frequency data by gender for all PDR questions. Table 2 shows the percent of men vs. women who indicated wearing a specific type of PDR clothing at least once a week or more. Two questions (clothing that is itchy or scratchy, clothing that restricts

Table 3 Gender Differences in "Ever Wearing" PDR Clothing Types (Study 2, MTurk Sample)

\begin{tabular}{|c|c|c|c|c|}
\hline Do you ever wear... & Women & Men & & Cramer's V \\
\hline 1. shoes that cause pain or blisters? & $56(42 \%)$ & $24(20 \%)$ & $* * *$ & .24 \\
\hline 2. clothing that causes discomfort because it is itchy or scratchy? & $30(23 \%)$ & $19(16 \%)$ & & .09 \\
\hline 3. clothing that you have to regularly adjust or monitor to keep it in the right place? & $71(55 \%)$ & $36(30 \%)$ & $* * *$ & .24 \\
\hline 4. clothes that make it hard to move your arms freely? & $19(14 \%)$ & $15(12 \%)$ & & .03 \\
\hline 5. clothes that make it hard to walk or move your legs freely? & $26(20 \%)$ & $16(13 \%)$ & & .08 \\
\hline 6. clothes that make it difficult to bend over? & $34(26 \%)$ & $19(16 \%)$ & & .12 \\
\hline 7. clothes that leave red marks/welts on your body after you take them off? & $42(32 \%)$ & $20(17 \%)$ & $* *$ & .17 \\
\hline 8. tight-fitting clothes that make it hard to take deep breaths? & $19(15 \%)$ & $7(6 \%)$ & & .14 \\
\hline $\begin{array}{l}\text { 9. dresses or skirts that you have to monitor so that they don't blow up (or flip up) and reveal more } \\
\text { skin than you wish to show? }\end{array}$ & $60(46 \%)$ & $\mathrm{n} / \mathrm{a}$ & & \\
\hline $\begin{array}{l}\text { 10. clothes that you have to be careful in because there is a risk of unintentionally exposing your } \\
\text { breasts? }\end{array}$ & $46(35 \%)$ & $\mathrm{n} / \mathrm{a}$ & & \\
\hline 11. clothes that make you too hot (or too covered) for weather conditions? & $59(45 \%)$ & $48(40 \%)$ & & .05 \\
\hline 12. clothes that make you too cold (or too uncovered) for weather conditions? & $44(34 \%)$ & $33(28 \%)$ & & .07 \\
\hline 13. shoes that limit how long you can comfortably stand? & $59(45 \%)$ & $22(18 \%)$ & $* * * *$ & .28 \\
\hline 14. clothing that you have to be careful in because it can drag on the ground? & $31(24 \%)$ & $14(12 \%)$ & & .16 \\
\hline 15. accessories (e.g., bracelets, earrings, necklace, watch) that can catch on things? & $80(61 \%)$ & $33(28 \%)$ & $* * * *$ & .34 \\
\hline
\end{tabular}

Asterisks indicate $p$-values for chi-square tests

$* * p<.01$; *** $p<.001$; **** $p<.0001$. 
breathing) were excluded from chi-square analyses for not meeting the assumption of at least five participants per cell. As in Study 1, the most frequently worn types of PDR items for both men and women were accessories that can catch on things ( $40 \%$ of women and $23 \%$ of men wearing at least once per week) and clothing that requires regular monitoring or adjusting (27\% of women and $16 \%$ of men wearing at least once per week). Twenty-eight percent of men $(n=33)$ and 8 percent of women $(n=10)$ reported wearing none of the types of PDR clothing.

Body Appreciation, Body Surveillance, and PDR Clothing. As in Study 1, men's and women's body appreciation scores did not significantly differ, men: $M=3.7, S D=.9$; women: $M=3.6$, $S D=.9, t(248)=.46, p=.65, d=.07,95 \%$ CI $[-.17, .28]$. Also consistent with Study 1, women reported significantly higher levels of body surveillance $(M=4.1, S D=1.3)$ compared to men, $M=3.5, S D=1.4, t(243)=3.45, p<.001, d=.44,95 \%$ CI $[.26, .95]$.

For 9 of the 13 PDR types tested, there was a significant main effect of gender on body surveillance $(p s \leq .005)$, with women scoring significantly higher than men. Results revealed a significant main effect of wearing PDR clothing on body surveillance at the .01 level for 8 of the 15 clothing types ( $p s \leq .009$; see Figs. 1 and 2 for effect sizes with confidence intervals). These PDR types were clothing that restricts bending, clothing that restricts arms, clothing that restricts legs, shoes that limit standing, clothing that restricts breathing, clothing that leaves red marks/welts, clothing that leaves one too cold/uncovered, and dresses or skirts that require monitoring. As in Study 1, no interactions met the $p<.01$ threshold for significance, so we discuss PDR results on body surveillance collapsed across gender.

For all significant effects, respondents who wore the PDR clothing type had higher body surveillance than those who did not. Cohen's $d$ s indicated that four effects (restrict bending, restrict breathing, restrict arms, restrict legs) were in the moderate to large range $(.60 \leq d s \geq .77)$ and the remaining four (red marks/welts, monitor skirt/dress, shoes limit standing, too cold/uncovered) were in the small to moderate range $(.39 \leq d s \geq .47)$. Full results for all ANOVAs are in the supplementary materials.

For body appreciation, results indicated no main effects of gender ( $p s \geq .25)$. One PDR clothing type (clothing that requires adjusting or monitoring) showed a significant main effect on body appreciation, $F(1,243)=7.43, p=.007$. Cohen's $d$ revealed this was a moderate effect $(d=.35)$, whereby those who indicated they wear clothing that requires adjusting or monitoring had lower body appreciation than those who did not.
Reasons for Wearing PDR Clothing. Responses to the openended item about reasons for wearing PDR clothing were coded for themes. We generated the first three themes in our codebook (see here) a priori. Based both on the predictions of objectification theory, specific literature focusing on PDR elements of women's clothing (e.g., Jeffreys, 2015), and evidence that women are more driven by appearance considerations when selecting clothing (Taylor \& Cosenza, 2002), we expected that many women's responses would identify appearance-based reasons for wearing PDR clothing. We also anticipated that some participants would reference explicit or implicit guidelines associated with the workplace (Levi, 2008; Nayak et al., 2015). Finally, given expectations for specific attire for some social settings or occasions, we included a theme focused on the requirements or pressures linked with these settings. Next, both authors immersed themselves in the data by reading all open-ended responses. We identified responses that referred to practical obstacles that necessitated wearing PDR clothing when one did not wish to do so (e.g., due to weight gain, the inability to purchase better-fitting clothing, difficulties finding clothing that fits one's body shape, not having clean laundry available). Thus, we added a fourth theme that captured these responses.

We reviewed the codebook with a team of six research assistants (all women). The research assistants coded 40 randomly selected responses using the codebook. Discussion of this process resulted in minor edits to the codebook to clarify that the "practical obstacles" theme could also include responses indicating that the participant had not had the time or opportunity to purchase more comfortable clothing. Finally, the first author trained two research assistants (both women who were not part of the initial codebook development or testing) to use the codebook. Each of these two research assistants independently coded the entire data set. Coding was conducted blind to participants' gender, though gender was often easily inferred from the response. Each participants' response could be coded into multiple categories. For example, if the person mentioned "formal occasions like weddings" and "to present a professional impression on people I do business with," the responses would be coded as including both the workplace and social setting themes. We excluded responses indicating that the participant did not wear PDR clothing (e.g., "I don't wear this kind of clothing," or "n/a") and three responses that speculated about why others wear PDR clothing. That left 178 responses to code (103 from women and 75 from men). Agreement between the two raters (evaluated using Krippendorff's alpha; Krippendorff, 2011) was high. Minimal discrepancies were resolved through discussion with the first author. See Table 4 for percent agreement between raters and 
Table 4 Reasons for Wearing PDR Clothing: Sample Responses for Each Theme and Estimates of Inter-rater Reliability (Study 2)

\begin{tabular}{|c|c|c|c|}
\hline Theme & $\begin{array}{l}\text { Krippendorff's } \\
\text { alpha }\end{array}$ & $\begin{array}{l}\text { Percent agreement } \\
\text { between raters }\end{array}$ & Sample responses \\
\hline Appearance-based reasons & .89 & $98 \%$ & $\begin{array}{l}\text { I try to find clothes that look good on me, sometimes they are not comfortable } \\
\text { but it makes me feel like I look good to other people } \\
\text { Because it is style or looks good on me or makes me feel sexy } \\
\text { It's worth the sacrifice of comfort to feel like I look good for this outing }\end{array}$ \\
\hline $\begin{array}{l}\text { Workplace requirements/ } \\
\text { pressures }\end{array}$ & .87 & $96 \%$ & $\begin{array}{l}\text { I have to wear a certain level of business attire for work, and sometimes these } \\
\text { items (shoes in particular) can be uncomfortable. But it is expected that I } \\
\text { will wear a suit and heels for my job } \\
\text { I wear these type of clothes when I have to for work. If I am doing a presenta- } \\
\text { tion or have to dress up formally for something, I wear clothes that are not } \\
\text { the most comfortable } \\
\text { Dress codes at certain companies I am working with }\end{array}$ \\
\hline Social settings/occasions & .85 & $95 \%$ & $\begin{array}{l}\text { Events like weddings where you have to look sharp-it comes at a price and } \\
\text { you always have that tie around your neck or the shoes that are very rigid } \\
\text { and cause tons of pain after an hour } \\
\text { Wearing a suit, for a funeral or wedding } \\
\text { Sometimes the clothing/shoes just work for the occasion (for example, a pair } \\
\text { of heels that hurt/cause blisters that go with a dress you are wearing for a } \\
\text { special occasion) }\end{array}$ \\
\hline Practical obstacles & .82 & $89 \%$ & $\begin{array}{l}\text { I know I can get clothes that fit me better in higher end stores, but I cannot } \\
\text { afford them } \\
\text { I have put on so much weight that some of my clothes don't fit like they should } \\
\text { I'm very petite, which means that clothes are either too long, cut low, or } \\
\text { otherwise ill-fitting } \\
\text { Laundry isn't done }\end{array}$ \\
\hline
\end{tabular}

Krippendorff's alpha for each of the four themes along with sample responses for each theme.

Among those who ever wear PDR clothing, the most commonly included theme was "practical obstacles" (45\% of men; $41 \%$ of women). In other words, many participants indicated that they sometimes wore PDR clothing not because they were trying to look attractive or because they were required to do so in a particular setting, but rather because, for a variety of practical reasons, they simply did not have other clothing options available. There was not a significant gender gap for this theme, $\chi^{2}(1)=.37, p=.54$, Cramer's $\mathrm{V}=.05$. Participants also frequently noted appearance-based reasons for wearing PDR clothing (49\% of women and $28 \%$ of men). Women who wear PDR clothing were significantly more likely to list this reason than men who wear PDR clothing, $\chi^{2}(1)=7.64, p=.006$, Cramer's $\mathrm{V}=.21$. The next most common reason for wearing PDR clothing was because it was called for by a specific type of social occasion or setting (most commonly, participants listed weddings). Eighteen percent of women who wear PDR clothing wrote a response that included this theme; $21 \%$ of men who wear PDR clothing did so. This difference was not statistically significant, $\chi^{2}(1)=.23, p=.63$, Cramer's $\mathrm{V}=.04$. Finally, participants also indicated that they wore
PDR clothing because it was expected in the workplace (12\% of women and $28 \%$ of men). Men were significantly more likely to list this as a reason than women, $\chi^{2}(1)=7.68$, $p=.006$, Cramer's $\mathrm{V}=.21$. This finding did not appear to be due to differential rates of employment between men and women, as it remained consistent when including only participants who work full-time $(p=.01)$ or only participants working either full- or part-time $(p=.007)$.

\section{Discussion}

Once again, we found that women were substantially more likely to wear PDR clothing than men. Wearing PDR clothing was linked to greater body surveillance among both women and men. In general, there was no pattern to suggest that body appreciation differed significantly between those who do and do not wear PDR clothing.

Coding of themes in the open-ended responses to the question about why participants wore PDR clothing suggested two areas of gender discrepancy. Consistent with evidence that women score higher than men on measures of the salience of appearance in their lives (Cash et al., 2004), 
and with arguments that women face more rigid appearance ideals than men (Buote et al., 2011), women who wore PDR clothing were more likely than men who wore PDR clothing to indicate that they did so in order to appear more attractive. On the other hand, men were more likely than women to indicate that when they wore PDR clothing, they did so because it was a workplace requirement (e.g., wearing a tie or suit jacket). This finding was somewhat surprising given the attention in both popular media and legal settings to sexist workplace apparel requirements (e.g., requiring women to wear heels or skimpy uniforms; Aamodt, 2017). It is possible that for some men, PDR clothing in the workplace (e.g., wearing a tie or blazer) can be a means of projecting power and financial success, both of which are tied to masculinity pressures (Berdahl et al., 2018). However, a more parsimonious explanation for this pattern (and one that is consistent with objectification theory), is that for women, the pressure to "look good" extends across all settings. In other words, if one's reason for wearing PDR clothing is to look attractive to others, that reason might supersede any specific reference to work or particular social settings. Unfortunately, the brief responses to this exploratory, open-ended question did not provide us with enough detail to more fully examine these possibilities.

\section{General Discussion}

Across two studies, we demonstrated that women are significantly more likely than men to wear clothing that is painful, distracts, or restricts movement. Additionally, results revealed that overall, men and women who wear PDR clothing engage in more body surveillance than men and women who do not wear this type of clothing. Finally, we found that when they wear PDR clothing, women are more likely to indicate that their reason for doing so is to look attractive to others, whereas men were more likely to indicate that they do so out of a workplace obligation. This descriptive, exploratory research is the first we are aware of that directly examines how often men vs. women wear PDR clothing.

These results may appear obvious to many readers. One would need only a passing familiarity with women's fashions to ascertain that they regularly show little regard for comfort or function. As just one example, consider widespread popular media coverage of the claim that the lack of pockets in women's clothing is an issue of gender equality (Basu, 2014), and that designers leave useful pockets off women's clothing primarily because pockets are viewed as unflattering to the lower body. Despite how easy it may be to casually observe the gender difference in wearing PDR clothing, documenting this pattern is a necessary first step in building an understanding of how often individuals wear PDR clothing, the psychological (or practical) factors involved in decisions to wear such clothing, and the psychological outcomes that follow.

Certainly, men's clothing can fall under the umbrella of painful, distracting, or restricting as well. For example, neckties are a common source of fashion-related discomfort for men. However, as workplaces become more casual, fewer men are required to wear ties on a regular basis. A 2007 Gallup poll found that two in three men never wear a tie to work and only nine percent wear a tie most days (Carroll, 2007). Rates are likely substantially lower today.

Though men in the current studies were less likely than women to wear PDR clothing, men and women who wore PDR clothing tended to have greater body surveillance than those who did not wear such clothing. The link between body surveillance and wearing PDR clothing could be conceptualized as moving in two directions. Some types of PDR clothing literally require body surveillance (e.g., clothing that must be adjusted/monitored in order to avoid showing more of your body than you mean to). For example, if a woman wears a low-cut blouse but does not wish to expose her breasts, that blouse will cause her to monitor her body in order to determine how much of it is visible to other people. Other types of PDR clothing may be more of a reflection of ongoing body surveillance. For example, women may wear "shapewear" in part because they are sensitive to how the shape of their body appears to others. Of course, these effects could also act in a feedback loop, where trait levels of body surveillance prompt a person to choose PDR clothing, and the PDR clothing itself then draws more of that person's attention to the appearance of their body.

The chronic appearance monitoring assessed by the measure of body surveillance used in these studies is strongly linked to self-objectification (Calogero, 2012). Selfobjectification has negative psychological outcomes for men as well as women (e.g., Hebl et al., 2004; Martins et al., 2007), suggesting that the potential psychological toll of body surveillance is relevant regardless of gender. However, because women report wearing PDR clothing substantially more frequently than men do, PDR clothing can be conceptualized as a factor that may partially explain the gender gap in rates of self-objectification (with women consistently reporting higher levels; Frederick et al., 2007).

Because one component of body appreciation is a focus on and appreciation for the functions of one's body (Tylka \& Wood-Barcalow, 2015), and because many types of PDR clothing can limit some of the body's functions (e.g., comfortable movement, taking deep breaths), we anticipated that wearing PDR clothing would be negatively associated with body appreciation. However, we found inconsistent support for this prediction. This may be because appreciation for the body's functionality is only one of several components of body appreciation. Other components (e.g., 
body acceptance and rejecting unhealthy or rigid appearance ideals; (Tylka \& Wood-Barcalow, 2015) may be less relevant to decisions around PDR clothing. An alternative explanation for the inconsistency of results regarding the link between PDR clothing and body appreciation is the complicating factor of choice. Regardless of whether you freely choose to wear PDR clothing or are required to do so (by a workplace, for example), body surveillance is a logical outcome of PDR clothing if it draws your attention to how you look. On the other hand, one can imagine a person with high levels of body appreciation who wears PDR clothing out of obligation. In this case, there is no reason to suspect that wearing PDR clothing would necessarily lower one's body appreciation.

The pattern of gender differences across these two studies with respect to how often men vs. women wear PDR clothing was clear: women wear such clothing more often. However, some categories of PDR clothing showed larger and more consistent gender differences. Across both studies, some of the largest differences between men and women were in wearing shoes that cause pain/blisters and wearing shoes that limit the time one can comfortably stand. The findings regarding shoes may speak to gender differences in taking a functional perspective on one's body (Alleva \& Tylka, 2021). When it comes to facilitating movement, shoes are arguably the single most important article of clothing. Shoes affect how quickly and confidently one can walk and how long one can stand without breaks. Though men's shoes vary to some extent in terms of how comfortable they are (e.g., dress shoes vs. running shoes), only in women's fashion do we see the dominance of a type of shoe (the high heel) that clearly impedes movement (Jeffreys, 2015). Previous research has found that women report wearing high heels in order to look sexy (Smolak et al., 2014), suggesting that shoes may be a key area where women negotiate tradeoffs between comfort and appearance pressures. Consistent with this argument, across both studies, those who reported wearing shoes that cause pain/blisters or limited the time they could comfortably stand scored significantly higher on body surveillance.

A second area of notable gender differences was in wearing clothing that requires adjusting or monitoring throughout the day: women were much more likely to indicate that they wore this type of clothing. This finding is consistent with Fredrickson and Roberts (1997) argument that certain women's fashions require women to be "chronically vigilant" of their bodies (p. 182). Monitoring your clothing provides ample opportunity to bring your attention back to your appearance. Interestingly, this type of PDR clothing was the only one to show a significant link with body appreciation across both studies. Men and women who indicated they wore clothing that requires this type of ongoing monitoring reported lower body appreciation.
One of several questions the current research leaves unanswered is the extent to which women freely choose to wear PDR clothing. This is a complicated question to tackle. In a culture in which women are taught that their primary form of social currency is their appearance (Fredrickson \& Roberts, 1997), the behaviors women engage in in order to appear attractive or sexy are at best viewed as constrained choices. Some women in Study 2 directly stated that they choose to endure fashion-related pain and discomfort because that is what it takes to look sexy. Even in settings where specific types of apparel are not explicitly required, social pressures to follow fashion trends can be fierce. A norm-enforced unofficial dress code (e.g., wearing tight, short dresses in order to gain entry to a trendy bar or wearing heels for an important work presentation) can still exert a substantial pull on behavior.

An important point of difference between men's and women's PDR clothing is that for women, PDR clothing is often revealing (e.g., tight, short, or low-cut clothing; Goodin et al., 2011), not just distracting or uncomfortable. In other words, much of women's PDR clothing seems intended to draw the (potentially sexually objectifying) gaze of others, whereas men's PDR clothing is often intended to signal competence or power (e.g., a suit coat and tie). Consistent with this trend, in the current studies, the only PDR clothing type men were more likely than women to report wearing at least once a week was clothing that makes one too hot or too covered for weather conditions (Study 1). This difference between revealing and non-revealing PDR clothing likely matters in terms of the subjective experience of wearing such clothing. A suit can hide perceived bodily flaws and make a person feel (and be perceived as) more powerful (Kraus \& Mendes, 2014); highly revealing clothing can prompt body consciousness and make a person more likely to be perceived as a sexual object (Gray et al., 2011).

\section{Limitations and Future Research Directions}

The current studies were primarily exploratory and cannot provide conclusive evidence about the direction of the association between wearing PDR clothing and body surveillance. Additionally, the limited data about reasons why men and women wear PDR clothing suggests that a more thorough analysis on this topic is warranted. Some reasons for wearing PDR clothing (e.g., to look good) seem to indicate free (or at least, somewhat free) choice. Other responses suggest bowing to social norms or following explicit guidelines for different work/social settings. Many participants listed both types of reasons. Future work on this topic should include a more nuanced set of questions about when, why, and how often men and women wear PDR clothing. This is especially important given the relatively informal process by 
which the list of PDR clothing types used in these studies was generated. Future researchers could consider using these initial data to inform the development of a formal measure of behaviors and attitudes around PDR clothing. The general categories of PDR clothing examined in these studies could also be used as a starting point for a more detailed analysis of specific articles of clothing and their psychological effects. For example, researchers could examine what types of clothing participants are thinking of when they respond to questions about clothing that leaves welts or makes it difficult to breathe. Of particular interest would be any gender differences in the extent to which PDR categories are capturing rarely worn types of clothing (e.g., formalwear) vs. more everyday types of clothing (e.g., undergarments, shoes).

We recommend that future work examining reasons why individuals wear PDR clothing employ focus groups or semi-structured interviews in order to more carefully interrogate how people make decisions around PDR clothing. Though many participants in the current study indicated that they wore PDR clothing to be more attractive to others, we were not able to explore how (or to what extent) men and women understood these choices in terms of gender roles or gendered sociocultural appearance ideals. In addition to this type of qualitative work, researchers should consider using experimental methods to test the extent to which wearing PDR clothing might lead to trade-offs between momentary boosts in self-esteem (e.g., feeling sexy or confident while wearing heels) and disruptions in the ability to focus (e.g., when one's attention is drawn to foot pain or the need to adjust one's clothing).

The current studies are also limited by their reliance on participants' memory and on participants' rough estimates of how often they wear different types of apparel. Additionally, our online survey did not include attention checks (beyond evaluating the open-ended responses in Study 2). Observational or field studies could provide more detailed data on the types of PDR clothing men and women wear in their everyday lives and how PDR clothing choices vary by setting or context. Some researchers have argued that those whose bodies least resemble cultural body ideals (typically people in marginalized bodies) may feel the greatest pressure to engage in appearance surveillance (Frederick et al., 2007). Relatedly, others have pointed to appearance management behaviors as a means for women who are poor to attempt to improve their status or financial situation (Edmonds, 2007). Together, these findings suggest that the links between social status and choices around PDR clothing would be a rich area for future research.
The current studies were not designed in a way to allow for a rigorous examination of how age (or the interaction between age and gender) might be related to wearing PDR clothing. However, there are numerous reasons that this could be an interesting area for future work. There are theoretical and empirical reasons to predict that women may be less likely to wear PDR clothing as they age. For example, Fredrickson and Roberts (1997) argued that because older women tend to receive less sexualized attention from their culture, women may find themselves more able to "step out of the objectification limelight," (p. $195)$ as they age. To the extent that they do so, they may feel less pressure to wear PDR clothing. This possibility would be consistent with evidence that older women report lower levels of self-objectification than young women (Tiggemann \& Lynch, 2001).

On the other hand, (Tiggemann, 2004) argued that, unlike age-related body changes, appearance management behaviors like clothing choices remain largely under one's control as one ages. For that reason, clothing choices designed to maximize attractiveness may become more important for women as they age. This perspective suggests that PDR clothing could be more common among older women.

\section{Practice Implications}

Therapists and other practitioners working with individuals who struggle with body image-related issues might consider clothing choices as a worthwhile topic to address. Previous research has suggested that a more functional approach to understanding one's body can help reduce body image disturbance (Alleva et al., 2015). To the extent that more comfortable clothing choices allow one to focus more on how one's body moves and how it feels, opting out of PDR clothing could be a healing choice for some (assuming they have the freedom and means to do so). This may be particularly true for women, both because women are more likely than men to wear PDR clothing and because women tend to engage in more body surveillance than men. Of course, practitioners should take care to avoid shaming people over any clothing choices, instead considering how one might select apparel that is both confidence-inducing and allows for comfortable freedom of movement and less distraction. Activists working in this space can continue to push fashion designers and clothing manufacturers to provide comfortable clothing that does not require monitoring and adjustment throughout the day - and insist that such options be available to all genders and all body shapes and sizes. 


\section{Conclusions}

The current studies are the first to offer empirical evidence that women are much more likely than men to wear painful, distracting, or restricting clothing. Though it might be tempting to dismiss this pattern as superficial or obvious, this gender discrepancy likely both reflects and contributes to the gender gap in self-objectification. These gendered differences in clothing are a reminder of the many ways that the cultural objectification of women can shape women's everyday lives.

\section{Appendix}

\section{Full PDR Questionnaire}

First, participants were asked, "Do you ever wear..." with respect to the relevant type of PDR clothing. Only those who responded "yes" were shown the follow-up question regarding frequency. The wording and response scale shown below for the sample item (in italics) was identical for each of the types of PDR clothing.

Sample Item:

Do you ever wear shoes that cause pain or blisters? (Yes/ No).

[If yes] On average, how often do you wear shoes that cause pain/blisters?

(1) - Less than once a month

(2) - Once a month

(3) - 2-3 times per month

(4) - Once a week

(5) - 2-4 times a week

(6) - Every day or nearly every day

1. shoes that cause pain/blisters?

2. clothing that causes discomfort because it is itchy or scratchy?

3. clothing that you have to regularly adjust or monitor to keep in the right place?

4. clothes that make it hard to move your arms freely?

5. clothes that make it hard to walk or move your legs freely?

6. clothes that make it difficult to bend over?

7. clothes that leave red marks/welts on your body after you take them off?

8. tight-fitting clothes that make it hard to take deep breaths?

9. dresses or skirts that you have to monitor so that they don't blow up (or flip up) and reveal more skin than you wish to show?*
10. clothes that you have to be careful in because there is a risk of unintentionally exposing your breasts?*

11. clothes that make you too hot (or too covered) for weather conditions?

12. clothes that make you too cold (or too uncovered) for weather conditions?

13. shoes that limit how long you can comfortably stand?

14. clothing that you have to be careful in because it can drag on the ground?

15. accessories (e.g., bracelets, earrings, necklace, watch) that can catch on things?

*These questions were only shown to women.

\section{Declarations}

Research involving human participants and/or animal All procedures performed in both studies were in accordance with the ethical standards of the institutional review board at Northwestern University and with the1964 Helsinki declaration and its later amendments.

Informed consent It was obtained from all individual participants included in the study.

Conflicts of Interest The authors declare that they have no conflict of interest.

\section{References}

Aamodt, M. (2017, January 1). Really, I come here for the food: Sex as a BFOQ for restaurant servers. The Industrial-Organizational Psychologist, 54(3). https://www.siop.org/Research-Publications/TIP/ TIP-Back-Issues/2017/January/ArtMID/20301/ArticleID/1624/ Really-I-Come-Here-for-The-Food-Sex-as-a-BFOQ-forRestaurant-Servers

Alleva, J. M., Martijn, C., Van Breukelen, G. J. P., Jansen, A., \& Karos, K. (2015). Expand Your Horizon: A programme that improves body image and reduces self-objectification by training women to focus on body functionality. Body Image, 15, 81-89. https:// doi.org/10.1016/j.bodyim.2015.07.001

Alleva, J. M., \& Tylka, T. L. (2021). Body functionality: A review of the literature. Body Image, 36, 149-171. https://doi.org/10.1016/j. bodyim.2020.11.006

American Psychological Association. (2007). Report of the APA Task Force on the sexualization of girls. http://www.apa.org/pi/women/ programs/girls/report-full.pdf

Andrew, R., Tiggemann, M., \& Clark, L. (2015). The protective role of body appreciation against media-induced body dissatisfaction. Body Image, 15, 98-104. https://doi.org/10.1016/j.bodyim.2015. 07.005

Basu, T. (2014, September 30). The gender politics of pockets. The Atlantic. https://www.theatlantic.com/technology/archive/2014/ 09/the-gender-politics-of-pockets/380935/

Berdahl, J. L., Cooper, M., Glick, P., Livingston, R. W., \& Williams, J. C. (2018). Work as a masculinity contest. Journal of Social Issues, 74(3), 422-448. https://doi.org/10.1111/josi.12289

Buote, V. M., Wilson, A. E., Strahan, E. J., Gazzola, S. B., \& Papps, F. (2011). Setting the bar: Divergent sociocultural norms for 
women's and men's ideal appearance in real-world contexts. Body Image, 8, 322-334. https://doi.org/10.1016/j.bodyim.2011.06.002

Butler, S., \& Scheetz, M. (1998). Body perceptions of bulimic and nonbulimic groups. Perceptual and Motor Skills, 87(1), 108-110. https://doi.org/10.2466/pms.1998.87.1.108

Calogero, R. M. (2012). Objectification theory, self-objectification, and body image. In T. F. Cash (Ed.), Encyclopedia of Body Image and Human Appearance (2nd ed., pp. 574-580). Academic Press.

Calogero, R. M., Davis, W. N., \& Thompson, J. K. (2005). The role of self-objectification in the experience of women with eating disorders. Sex Roles, 52(1-2), 43-50. https://doi.org/10.1007/ s11199-005-1192-9

Carroll, J. (2007, October 4). "Business casual" most common business attire. Gallup. https://news.gallup.com/poll/101707/businesscasual-most-common-work-attire.aspx

Cash, T. F., Melnyk, S. E., \& Hrabosky, J. I. (2004). The assessment of body image investment: An extensive revision of the Appearance Schemas Inventory. International Journal of Eating Disorders, 35(3), 305-316. https://doi.org/10.1002/eat.10264

Edmonds, A. (2007). "The poor have the right to be beautiful": Cosmetic surgery in neoliberal Brazil. Journal of the Royal Anthropological Institute, 13(2), 363-381. https://doi.org/10.1111/j. 1467-9655.2007.00427.x

Engeln, R. (2017, October 27). Why care about a shoe emoji? Because women's fashion has real implications for our lives. The Washington Post. https://www.washingtonpost.com/news/posteverything/ wp/2017/10/26/why-care-about-a-shoe-emoji-because-womensfashion-has-real-implications-for-our-lives/

Engeln-Maddox, R. (2006). Buying a beauty standard or dreaming of a new life: Expectations associated with media ideals. Psychology of Women Quarterly, 30(3), 258-266. https://doi.org/10.1111/j. 1471-6402.2006.00294.x

Engeln-Maddox, R., Salk, R. H., \& Miller, S. A. (2012). Assessing women's negative commentary on their own bodies: A psychometric evaluation of the Negative Body Talk Scale. Psychology of Women Quarterly, 36(2), 162-178. https://doi.org/10.1177/ 0361684312441593

Fitzsimmons-Craft, E. E., Harney, M. B., Koehler, L. G., Danzi, L. E., Riddell, M. K., \& Bardone-Cone, A. M. (2012). Explaining the relation between thin ideal internalization and body dissatisfaction among college women: The roles of social comparison and body surveillance. Body Image, 9, 43-49. https://doi.org/10. 1016/j.bodyim.2011.09.002

Frederick, D. A., Forbes, G. B., Grigorian, K. E., \& Jarcho, J. M. (2007). The UCLA Body Project I: Gender and ethnic differences in self-objectification and body satisfaction among 2,206 undergraduates. Sex Roles(5-6), 57, 317-327. https://doi.org/10.1007/ s11199-007-9251-z

Fredrickson, B. L., Noll, S. M., Roberts, T. A., Quinn, D. M., \& Twenge, J. M. (1998). That swimsuit becomes you: Sex differences in self-objectification, restrained eating, and math performance. Journal of Personality and Social Psychology, 75(1), 269-284. https://doi.org/10.1037/0022-3514.75.1.269

Fredrickson, B. L., \& Roberts, T.-A. (1997). Objectification theory: Toward understanding women's lived experiences and mental health risks. Psychology of Women Quarterly, 21(2), 173-206. https://doi.org/10.1111/j.1471-6402.1997.tb00108.x

Frith, H., \& Gleeson, K. (2004). Clothing and embodiment: Men managing body image and appearance. Psychology of Men and Masculinity, 5(1), 40-48. https://doi.org/10.1037/1524-9220.5. 1.40

Gardner, R. M., Brown, D. L., \& Boice, R. (2012). Using Amazon's Mechanical Turk website to measure accuracy of body size estimation and body dissatisfaction. Body Image, 9, 532-534. https://doi.org/10.1016/j.bodyim.2012.06.006
Goodin, S. M., Van Denburg, A., Murnen, S. K., \& Smolak, L. (2011). "Putting on" sexiness: A Content Analysis of the presence of sexualizing characteristics in girls' clothing. Sex Roles, 65(1-2), 1-12. https://doi.org/10.1007/s11199-011-9966-8

Gray, K., Knobe, J., Sheskin, M., Bloom, P., \& Barrett, L. F. (2011). More than a body: Mind perception and the nature of objectification. Journal of Personality and Social Psychology, 101(6), 1207-1220. https://doi.org/10.1037/a0025883

Hebl, M. R., King, E. B., \& Lin, J. (2004). The swimsuit becomes us all: Ethnicity, gender, and vulnerability to self-objectification. Personality and Social Psychology Bulletin, 30(10), 1322-1331. https://doi.org/10.1177/0146167204264052

Homan, K. J., \& Tylka, T. L. (2015). Self-compassion moderates body comparison and appearance self-worth's inverse relationships with body appreciation. Body Image, 15, 1-7. https://doi. org/10.1016/j.bodyim.2015.04.007

Jeffreys, S. (2015). Beauty and misogyny: Harmful cultural practices in the West. Routledge.

Kraus, M. W., \& Mendes, W. B. (2014). Sartorial symbols of social class elicit class-consistent behavioral and physiological responses: A dyadic approach. Journal of Experimental Psychology: General, 143(6), 2330-2340. https://doi.org/10.1037/ xge 0000023

Krippendorff, K. (2011). Agreement and information in the reliability of coding. Communication Methods and Measures, 5(2), 93-112. https://doi.org/10.1080/19312458.2011.568376

Kwon, Y. H., \& Parham, E. S. (1994). Effects of state of fatness perception on weight conscious women's clothing practices. Clothing and Textiles Research Journal, 12(4), 16-21. https:// doi.org/10.1177/0887302X9401200403

Levi, J. (2008). Misapplying equality theories: Dress codes at work. Yale Journal of Law and Feminism, 19(2), 353-390. https:// digitalcommons.law.yale.edu/cgi/viewcontent.cgi?referer= https://www.google.com/\&httpsredir $=1 \&$ article $=1271 \&$ context=yjlf

Martin, K. A. (1998). Becoming a gendered body: Practices of preschools. American Sociological Review, 63(4), 494-511. https:// doi.org/10.2307/2657264

Martins, Y., Tiggemann, M., \& Kirkbride, A. (2007). Those speedos become them: The role of self-objectification in gay and heterosexual men's body image. Personality and Social Psychology Bulletin, 33(5), 634-647. https://doi.org/10.1177/0146167206297403

McKinley, N. M. (1998). Gender differences in undergraduates' body esteem: The mediating effect of objectified body consciousness and actual/ideal weight discrepancy. Sex Roles, 39(1-2), 113-123. https://doi.org/10.1023/A:1018834001203

McKinley, N. M., \& Hyde, J. S. (1996). The objectified body consciousness scale: Development and validation. Psychology of Women Quarterly, 20(2), 181-215. https://doi.org/10.1111/j. 1471-6402.1996.tb00467.x

Miner-Rubino, K., Twenge, J. M., \& Fredrickson, B. L. (2002). Trait self-objectification in women: Affective and personality correlates. Journal of Research in Personality, 36(2), 147-172. https:// doi.org/10.1006/jrpe.2001.2343

Moradi, B., \& Varnes, J. R. (2017). Structure of the Objectified Body Consciousness Scale: Reevaluated 20 years later. Sex Roles, 77(56), 325-337. https://doi.org/10.1007/s11199-016-0731-x

Murnen, S. K., Greenfield, C., Younger, A., \& Boyd, H. (2016). Boys act and girls appear: A content analysis of gender stereotypes associated with characters in children's popular culture. Sex Roles, 74(1-2), 78-91. https://doi.org/10.1007/ s11199-015-0558-x

Nayak, R., Padhye, R., \& Wang, L. (2015). How to dress at work. In S. Patole (Ed.), Management and Leadership - A Guide for Clinical Professionals (pp. 241-255). Springer International Publishing. https://doi.org/10.1007/978-3-319-11526-9_17 
Noll, S. M. (1996). The relationship between sexual objectification and disordered eating: Correlational and experimental tests of body shame as a mediator. (Publication No. 9704732) [Doctoral dissertation, Duke University] ProQuest Dissertations and Theses Global. http://search.proquest.com/docview/304348153/

Noll, S. M., \& Fredrickson, B. L. (1998). A mediational model linking self-objectification, body shame, and disordered eating. Psychology of Women Quarterly, 22(4), 623-636. https://doi.org/10. 1111/j.1471-6402.1998.tb00181.x

Parent, M. C. (2013). Handling item-level missing data: Simpler is just as good. The Counseling Psychologist, 41(4), 568-600. https:// doi.org/10.1177/0011000012445176

Parmentier, M. A. (2016). High Heels. Consumption Markets and Culture, 19(6), 511-519. https://doi.org/10.1080/10253866.2016. 1153830

Prichard, I., \& Tiggemann, M. (2005). Objectification in fitness centers: Self-objectification, body dissatisfaction, and disordered eating in aerobic instructors and aerobic participants. Sex Roles, 53(1-2), 19-28. https://doi.org/10.1007/s11199-005-4270-0

Reynolds, S. E., Richardson, S. V., Horne, B., Reid, I., Ross, R., \& Campbell, R. (2018). Where do we stand on high heels in 2018 ? An audit. Journal of Applied Mathematics and Physics, 6(4), 715-724. https://doi.org/10.4236/jamp.2018.64064

Rycroft-Smith, L. (2017, February). Switching to men's clothing taught me that the world doesn't want women to get too comfortable. Quartz. https://qz.com/916148/switching-to-mens-clothingtaught-me-that-the-world-doesnt-want-women-to-get-toocomfortable/

Schaefer, L. M., Burke, N. L., Calogero, R. M., Menzel, J. E., Krawczyk, R., \& Thompson, J. K. (2018). Self-objectification, body shame, and disordered eating: Testing a core mediational model of objectification theory among White, Black, and Hispanic women. Body Image, 24, 5-12. https://doi.org/10.1016/j.bodyim.2017.10.005

Schmider, E., Ziegler, M., Danay, E., Beyer, L., \& Bühner, M. (2010). Is It Really Robust?: Reinvestigating the robustness of ANOVA against violations of the normal distribution assumption. Methodology, 6(4), 147-151. https://doi.org/10.1027/1614-2241/a000016

Smith, H., Perez, M., Sladek, M. R., Becker, C. B., Ohrt, T. K., \& Bruening, A. B. (2017). Development and validation of makeup and sexualized clothing questionnaires. Journal of Eating Disorders, 5(1), 1-13. https://doi.org/10.1186/s40337-017-0171-1

Smolak, L., Murnen, S. K., \& Myers, T. A. (2014). Sexualizing the self: What college women and men think about and do to be "sexy." Psychology of Women Quarterly, 38(3), 379-397. https://doi.org/10.1177/ 0361684314524168
Stephens, D. L., Hill, R. P., \& Hanson, C. (1994). The beauty myth and female consumers: The controversial role of advertising. Journal of Consumer Affairs, 28(1), 137-153. https://doi.org/10.1111/j. 1745-6606.1994.tb00819.x

Stern, N. G., \& Engeln, R. (2018). Self-compassionate writing exercises increase college women's body satisfaction. Psychology of Women Quarterly, 42(3), 326-341. https://doi.org/10.1177/ 0361684318773356

Taylor, S. L., \& Cosenza, R. M. (2002). Profiling later aged female teens: Mall shopping behavior and clothing choice. Journal of Consumer Marketing, 19(5), 393-408. https://doi.org/10.1108/ 07363760210437623

Tiggemann, M. (2004). Body image across the adult life span: Stability and change. Body Image, 1, 29-41. https://doi.org/10.1016/ S1740-1445(03)00002-0

Tiggemann, M., \& Andrew, R. (2012). Clothes make a difference: The role of self-objectification. Sex Roles, 66(9-10), 646-654. https:// doi.org/10.1007/s11199-011-0085-3

Tiggemann, M., \& Kuring, J. K. (2004). The role of body objectification in disordered eating and depressed mood. The British Journal of Clinical Psychology, 43(3), 299-311. https://doi.org/10.1348/ 0144665031752925

Tiggemann, M., \& Lacey, C. (2009). Shopping for clothes: Body satisfaction, appearance investment, and functions of clothing among female shoppers. Body Image, 6(4), 285-291. https://doi.org/10. 1016/j.bodyim.2009.07.002

Tiggemann, M., \& Lynch, J. E. (2001). Body image across the life span in adult women: The role of self-objectification. Developmental Psychology, 37(2), 243-253. https://doi.org/10.1037/0012-1649. 37.2.243

Tylka, T. L., \& Wood-Barcalow, N. L. (2015). The Body Appreciation Scale-2: Item refinement and psychometric evaluation. Body Image, 12(1), 53-67. https://doi.org/10.1016/j.bodyim.2014.09. 006

Wood-Barcalow, N. L., Tylka, T. L., \& Augustus-Horvath, C. L. (2010). "But I Like My Body": Positive body image characteristics and a holistic model for young-adult women. Body image, 7(2), 106-116. https://doi.org/10.1016/j.bodyim.2010.01.001

Publisher's Note Springer Nature remains neutral with regard to jurisdictional claims in published maps and institutional affiliations. 